\section{Iwona Staniec}

(iD) https://orcid.org/0000-0002-5580-5450

Department of Management

Faculty of Management

and Production Engineering

Lodz University of Technology

Lodz, Poland

iwona.staniec@p.lodz.pl

\section{Joanna Pilawa}

D https://orcid.org/0000-0001-8193-1955

Department of Management

Faculty of Management

and Production Engineering

Lodz University of Technology

Lodz, Poland

joanna.pil96@gmail.com

\title{
The use of design thinking in the creation of academic incubators
}

Accepted by Editor Ewa Ziemba | Received: August 14, 2019 | Revised: January 2, 2020; March 9, 2020; April 8, 2020; May 18, 2020 | Accepted: June 30, 2020.

\begin{abstract}
Aim/purpose - More and more universities invest in business incubators. However, different aspects of their creation are not extensively described in the literature. The main purpose of this paper is to identify the possibility of using design thinking (DT) in the creation of academic incubators.

Design/methodology/approach - A case study is used in this research. The approach of Lodz Technical University to the creation of a business incubator by using the design thinking method is presented.

Findings - It is significant that all the participants thought design thinking was a useful methodology for the creation of academic incubators. Furthermore, the participants had a sense of social contribution to the local people, the university, and communities. It was very important to use their knowledge, experience, skills, and needs in the field of collaboration with incubators. The common works provided an opportunity to share their ideas with other teammates from different perspectives. The advantages of using DT are very meaningful for participants, allowing them to keep in mind why they are doing this and for whom. The DT process can be very difficult to describe, but its use by the creation of a business incubator will yield many benefits and new initiatives. DT is a great solution to this problem because it relates programme activities to their effect, it helps keep stakeholders focused on achieving outcomes, while it remains flexible and open to finding the best means to enact a unique story of change.
\end{abstract}


Research implications/limitations - The limitations of the described study are observer bias and difficulty of replication. The effect of this process was not implemented because there was insufficient funding and the decisions regarding the implementation of this idea have changed.

Originality/value/contribution - This paper is a one-of-a-kind description of the implementation of design thinking methodology in the creation of an academic incubator.

Keywords: design thinking, academic incubators, creation of incubators.

JEL Classification: M21, O31, O32.

\section{Introduction}

The literature perceives youth entrepreneurship as an important aspect from a social, economic, and political perspective (Bezerra \& Andreassi, 2017). What is more, the environment and current technologies are putting pressure not only on the business field, but also on students as well as the universities (Allahar \& Sookramthat, 2019; Kuratko \& Morris, 2018). Both graduate students and company workers need to possess new skillsets to address market requirements. As a response to those needs, university incubators are being created to foster the entrepreneurship potential of their students, alumni, and workers. The process of creating an incubator itself is an important issue, taking into consideration the current market saturation. Incubators are viewed as tools for promoting entrepreneurship and socioeconomic development through enhanced innovation, job creation, and social cohesion (Allahar \& Sookramthat, 2019; Bone, Allen, $\&$ Haley, 2017). Studies have shown that, despite some successful incubation experiences, only a modest resulting generation of start-ups is evident (Allahar \& Sookramthat, 2019). Nevertheless, university-led business incubators are considered critical to the supply of resources, the creation of formal networks, the facilitation of informal networks, and the development of new ventures (Allahar \& Sookramthat, 2019). Therefore, working out kinks in the development of the processes and tools facilitating cooperation between the incubator and different stakeholder groups is of vital importance.

When design thinking (DT) approaches are applied to business, the success rate for innovation improves substantially. Design thinking is a powerful process of problem solving that begins with understanding unmet customer needs. Design thinking effects a dynamic university ecosystem and self-regulating networks involving diverse players (Allahar \& Sookramthat, 2019; Malecki, 2017). 
There are a number of incubators that do not work effectively or do not use their potential to the fullest (Bone et al., 2017; Hackett \& Dilts, 2004; Mitra, 2013). This is why, especially in the case of academic incubators, which bear great potential, a good beginning is, as they say, 'half the battle.' However, no cases of the use of the DT method to create academic incubators are to be found in the literature.

The main purpose of this paper is to identify the possibility of using DT in creating academic incubators. This paper describes how young innovators (part of the stakeholders in the university ecosystem) can add value to the incubator, based on a case study conducted at Lodz University of Technology (TUL).

The world of engineering is focused on innovation because innovation is a crucial factor in development. Therefore, the research checks whether innovative solutions can be created with the use of design thinking as a problemsolving tool. Such an approach was used by TUL in the process of developing their business incubator. The university decided to invite all groups of incubator stakeholders to participate in creating the solutions, using the design thinking method, for the newly created incubator. The presented research concerns the first stage of the development of the incubator, the project of creating its basic offer, and the requirements of specialist knowledge on the part of the team working in the incubator (Saffar, 2008). These activities are to frame the incubator's activities from its first development phase and allow it to be focused on the needs of direct stakeholders.

This paper is divided into six main sections. Section 1 introduces the theme of the work and contains the defined research questions. Section 2 is an overview of the literature; the authors analyse the major viewpoints on the factors that determine the creation of academic incubators and the use of the DT method. Section 3 explains the research methodology. Section 4 presents the results of the observation and describes each part of the used method. Section 5 presents the discussion. Section 6, the conclusion, recaps the information of the paper and outlines opportunities for further research and limitations of the paper.

\section{Literature review}

\subsection{Creation of the incubator}

Higher education plays an important role in economic growth. It is most visible in the technology-based aspect of the economy. Universities function as research centres, and the technologies developed therein are potentially applica- 
ble in the business world. The great importance of incubators in the process of technology transfer at universities is often highlighted. Therefore, there is a huge opportunity for universities to contribute to economic improvement through incubators (Wicaksana, Yuniaristando, \& Sutopo, 2015). However, it was not always so. Controversies arise due to the belief that the purpose of universities is to teach and to do research just for the sake of knowledge, not commercial success (Siegel \& Wright, 2015). Conducting research necessitates funding, and therefore opponents of commercialising the university had to acknowledge that this new response was reasonable. Being forward-thinking, one can observe that a stronger stress on commercialisation and academic entrepreneurship would lead to increases in, and development within, the field of basic research (Siegel $\&$ Wright, 2015). This phenomenon occurs due to the fact that funds gained by commercialisation are largely ploughed back into research (Link \& Sarala, 2019). Taking such a cycle into consideration, it can be concluded that decrying the rise of commercialisation is misguided. Following the modern approach, the role of universities in the entrepreneurship ecosystem has become extremely relevant. In addition to the main roles of universities, which are teaching and research, nowadays the entrepreneurial role has become so important that it is defined as a third mission, which requires universities to actively take part in the economic development of regions, societies, or even nations (Link \& Sarala, 2019).

At this point, the idea of the triple helix model of innovation can be mentioned. It concerns the interactions between industry, government, and academia, with the purpose of fostering development (Leydesdorff, 2012). The university incubator is one of the ventures that was developed through those interactions. According to the Polish higher education act, academic business incubators are defined as entities created in order to support university employees', doctoral students', and students' business activities (Ustawa z dnia 20 lipca 2018 r. [Higher Education Act, 2018]).

An academic business incubator is a distinctive type of business incubator. It is treated as an extension of the teaching process, which aims at preparing for the creation of ventures and practical operation on the market. At the same time, it is a process of verification for acquired knowledge and skills. Incubators created at universities assist students and university workers in real market operations. Activities organised within incubators are oriented toward entrepreneurship education as well as commercialisation of new products or technologies, which are the effect of research conducted at the university (Siemieniuk, 2017). The popularity of university incubators is growing, and many universities have de- 
cided to invest in one. In 2017, there were as many as 20 academic incubators in Poland (Bąkowski \& Mażewska, 2018). The strategies and mechanisms employed by university incubators have an influence across all areas of academic entrepreneurship; for example, an incubation strategy can be used to support and influence faculty work, students on campus, and graduates who are now entrepreneurs - and create a hub for building connections and community (Sherwood, 2018).

There is a growing interest in academic incubators, but not all universities know how to start one or what to focus on. An incubator at Buffalo University in the United States is one example of a successful university incubator venture. Zablocki (2007), a specialist in the field of research administration at Buffalo at the State University of New York, presents the process of starting a business incubator. As stages of the preparation phase, which is a crucial part of the creation of an incubator, he distinguishes the following: the feasibility study, building support, identifying and securing stakeholders, and identifying a market niche.

The feasibility study, which is the first stage in the mentioned classification, refers to the assessment and analysis of the project's potential in order to support the decision-making process by rational and objective definition of the project's strengths, weaknesses, opportunities, and threats, as well as needed resources and the chances of its success (Russell \& Taylor, 2008). A properly performed study can provide needed information for the political and economic viability of the project. Additionally, Meeder points to a number of benefits of conducting a feasibility study, which, according to him: "helps to forge a consensus among key organisations and civic leaders; catalyses the involvement of organizations that can provide the incubator with a range of resources including facilities, funding, equipment, and human resources; allows for the completion of plans for both the facilities and the services to be provided; helps secure funding from government sources at all levels; educates public and private sector constituencies about business incubation in order to avoid confusion and unwarranted expectations; and provides an occasion to contact successful incubator programs in similar communities to learn their best practice lessons" (after: Zablocki, 2007, p. 1307).

The study should also provide warnings based on errors made by other incubator programmes concerning the governing board, funding, facility and site choice. A feasibility study should provide not only general analysis but also direct recommendations, which is also why it may be recommended to use a consultant who is experienced in the field of incubators. An appropriate feasibility study helps projects to proceed in a systematic manner and helps to secure funding through the development process (Zablocki, 2007). 
Another stage of preparatory work in creating an incubator is building support. An incubator is a community investment - it is done by people and for people; therefore, it requires strong and broad community support to be successful. A way of building support is by organising community meetings. Such meetings may provide information concerning the incubator industry, referrals to organisations or people eager to assist in the project. This process aims at clarifying the prospects for starting a new business incubator. It should help identify funding sources, facilities, and sources of support (Zablocki, 2007). The theory views a company as a bundle of resources: assets, competences, and skills. Possessing certain resources is crucial for obtaining a competitive advantage, but also for embarking on internationalisation. Academic incubators effectively support start-ups in these activities (Jankowska, 2015).

Identifying and securing stakeholders is also among the necessary preparation activities. By stakeholder we mean anyone (an individual or a group) who is affected or affects organisation's actions (Freeman \& Moutchnik, 2013). Each incubator is different, and the stakeholders differ as well. In the case of academic incubators, it may be anticipated that the stakeholders would include not only students or university management but also companies or any organisation interested in fostering entrepreneurship and business development. The support of stakeholders is crucial for a successful incubator programme. Stakeholders often have different visions and expectations, and it is important to have agreement concerning the goals and mission of the incubator in order for it to work in the most beneficial way.

Lastly, the key to success is to identify a market niche. In order to become part of the market, the academic incubator has to establish a unique purpose and find a place for itself. All businesses pay attention to positioning their products on the market and modifying said position in response to their customers' needs. The incubator needs to do the same to develop a market niche. To do that the incubator needs to offer something needed and at the same time something that answers those needs in a distinguishable way. This can be exemplified in the case of high-tech incubators, which serve a specific group of customers: technology-focused companies. The mix of offered services and resources are aspects that help the incubator to effectively position itself on the market. 


\subsection{The idea of design thinking}

Another important aspect of this paper is the idea of DT. The definition of DT is still to be clarified. Brown's (cited in Liedtka, 2014, p. 926) definition of design thinking was “bringing designers' principles, approaches, methods, and tools to problem-solving." While Thomas Lockwood, former president of the Design Management Institute, defines it as "a human-centred innovation process that emphasises observation, collaboration, fast learning, visualisation of ideas, rapid concept prototyping, and concurrent business analysis" (Liedtka, 2014, p. 926). It can also be considered as an iterative approach to problem-solving, which is characterised by focusing on empathy, user-centricity, integrative thinking, teamwork, and the implementation of various tools for ideation and visualisation (Fjuk \& Kvale, 2018). Several approaches for design thinking were developed, based on systematic steps design. These works mainly followed the Hasso Plattner Institute of Design at Stanford (d.school) approach. It distinguishes five steps: empathise, define, ideate, prototype, and test.

Empathy is a key factor in the customer-centred design process. This stage is for a designer or a design thinker to understand people within a challenging context. The aim is to understand why users do certain things and their emotional and physical needs, as well as getting a picture of users' visions of the world and users' values (Fjuk \& Kvale, 2018).

The define mode is the point where all previously gathered information is systematised and the challenge is defined. The goal of this stage is to create a meaningful problem statement. It plays the role of a guiding statement focusing on users' needs and insights (Schallmo, Wiliams, \& Lang, 2018). The ideate mode is the stage focused on generating ideas. It is about opening minds and creating new concepts. The ideate step provides the material for building prototypes and, as a result, providing users with an innovative solution (Schallmo et al., 2018).

The prototype stage is focused on the iterative generation of artefacts with the specific intention of answering users' needs and helping with the process of creating the final result. This is significant in its invocation of informative feedback from potential users or co-creators. The more precise the questions concerning users' needs, the more precise and refined the prototype should be (Schallmo et al., 2018).

The last part is the test mode, which is when the designer gathers feedback concerning prototypes from the users. Testing provides the researcher with another opportunity to understand the customer. Therefore, it is crucial to delve as deep as possible, so as not to limit the assessment of the prototype (Schallmo et al., 2018). 
There may be iteration of the whole process, but it can take place within each of these steps. Each cycle narrows down the focus, and the concept becomes more and more specific. Even though the process may be presented in a linear form, this is just for simplification (Hasso Plattner Institute of Design Stanford, 2010).

\section{Research methodology}

The research is based on a case study focusing on the analysis of the process of creating the incubator at TUL. The conducted research strives to answer the following research questions:

Q1: Was the selected method (DT) appropriate for the creation of the incubator at TUL?

Q2: Is design thinking a suitable tool for the development of the processes and tools facilitating cooperation between the incubator and the different groups of stakeholders?

The research covers the creation process based on design thinking. As a versatile method, DT is mainly used to create innovative solutions for complex problems with no simple answer. Due to the design thinking specifics, it operates mainly on qualitative data, striving to create a solution that fulfils the needs. In this project, we found the need for operational actions toward advancing the knowledge sharing and the coordination of business development initiatives.

The conducted research is in the form of a case study, which is a very useful method for exploring areas that are not known or about which little is known, as well as when the aim is to develop a holistic understanding of a phenomenon, situation, or group. This approach is of immense relevance in a situation when the study is focused on exploring and understanding more than confirming or quantifying (Kumar, 2011). The authors were observers of this process; they did not directly participate in it. They also worked only with the documentation collected during its course. Therefore, the case study method is the most suitable for this kind of problem (Apanowicz, 2001).

The benefit of the case-study method is that it enables a focus on a particular issue and long contact with the study situation or community. Moreover, it ensures a high specificity of analysis of the examined phenomenon and interdisciplinary character of the research processes being performed. It also allows for presentation of not only the current state of research, but also its lead-up history and background information through the analysis of a variety of confluent doc- 
umentation. The key problem in the usage of case studies is its qualitative character - as such, the research is prone to be distorted by the subjective view of the researcher (observers) (Kumar, 2011; Sztrumski, 2004).

In order to minimise such an effect in this work, the process of the research was divided into stages and described in detail according to the method of design thinking, which reduces the impact of biases and thereby the subjectivism of researchers (observers) (Liedtka, 2014). The authors were observers not directly involved in the process. Taking into consideration the characteristics of the study method and the examined problem, the choice seems to be suitable for its purpose.

\section{Research findings}

\subsection{Study background}

In the year 2018 Grzegorz Kierner - director of the Centre for Cooperation with Economy, Innovations, and Technology Transfer at TUL - initiated the idea of creating a business incubator at the Technical University of Lodz. Thanks to his experience, the originator was aware of the benefits of the venture, which was also a trigger for raising the issue. The idea was developed in cooperation with the Academic Career Centre and Grzegorz Liśkiewicz, who is the rector's plenipotentiary responsible for entrepreneurship. It was decided that the idea should be developed because students of TUL have great potential, which was proven by winning a number of competitions for innovative solutions and the fact that many of them start their own businesses. Moreover, such a step provides a great opportunity for university development and adjustment to current trends, which state that the universities are to be more business oriented.

Julia Skrzypkowska, as a representative of the career centre, together with company Klientocentryczni (an outside company specialising in DT methodology), decided to perform design thinking workshops and conscript a team to analyse the outcomes in order to find a way to create a unique incubator and to design new, effective mechanisms linking business with science within the limits of the incubator of entrepreneurship. The objectives of the workshop were the development of processes and tools to facilitate cooperation between the incubator and the different groups of stakeholders. 
Invited participants included people from four fields, who, coincidentally, were actors in the incubator's target market: business environment organisations, small companies or start-ups, students, and big companies. Four teams (each with four persons) were created, comprising representatives from each group. The described work with groups was initiated on 23 October 2018 and lasted four weeks. Expert voting for projects was carried out on 29 November 2018. The next step in the assessment was a public survey that was initiated on 20 April 2019 (still ongoing at the time of the description).

There are a number of threats to this venture, and therefore the design thinking process was introduced to fight them. One of the issues is the fact that the market is saturated, and it is huge. Due to the market saturation, the idea creation must be outstanding and ahead of customers' expectations. Another threat is the issue of obtaining the necessary funds for such large investments.

\subsection{Workshops}

In Lodz alone, there are about 10 business incubators and entrepreneurship accelerators (Urząd Miasta Łodzi, s.a.); hence, while creating the incubator for TUL, it was necessary to make it outstanding. Because the target group in this particular case is vast and consists of various subgroups, the opinions and ideas of students alone give a rather narrow view. That is why representatives of all subgroups (small start-ups, big businesses, business environment organisations) were invited to take part in the DT workshops. The aim of this venture was to formulate an idea for the development of the incubator. There were four groups created, each consisting of four volunteers from different fields. Forming the multidisciplinary teams is one of the significant characteristics of DT because it broadens the participants' minds through interaction with the participants from different degree subjects, and it encourages them to collaborate, utilising their strength in a project.

Workshops were organised with the help of a company called Klientocentryczni (two staff persons) and consisted of three meetings. Each meeting lasted eight hours.

The first meeting was dedicated to creating unique teams, taking into consideration knowledge competencies and experience. Next, the theoretical introduction concerning DT methodology took place. Finally, the guidelines of conducting interviews were introduced, and the participants were given a set of opening questions. 
The second meeting focused on analysing interview outcomes, identifying users' problems, and creating innovative solutions to satisfy the needs of the respondents.

The third and final meeting was a time for gathering feedback - concerning ideas - from the potential users. During this time, concepts were polished and the interactive prototypes were created. Those prototypes were later presented to the people directly involved in the creation of the incubator. They provided some feedback and considered the ideas from the point of view of feasibility.

According to the most popular DT stage divisions, the workshop stages were divided accordingly into: empathise, define the problem, ideate, prototype, and test. However, the participant was able to continually revisit other phases when needed. For example, the participants could return to the empathy phase to talk to the users again from the prototyping phase if they doubted their ideas were creating new user experiences while they were creating mock-ups for visualisation of their ideas. They were able to talk to their users again to better understand their hidden needs, in order to reframe the problems.

\section{Empathise}

The first stage of the design thinking process focuses on gaining crucial knowledge about the user, its situation, and problems. For this reason, the teams were asked to construct and conduct interviews as well as create an empathy map. The groups prepared interviews and conducted them in pairs (note taker and interviewer) with the representatives of the assigned focus group.

An empathy map is a tool that is widely used for the creation of a user persona. It should contain the key problem and expected benefits from problem solving. It should also include information about the hypothetical customer or user, their name, and some details about who they are, what they are doing, seeing, hearing, or feeling (Bland, 2016). However, there is no documentation because they were deconstructed and reused in further steps for the benefit of other tools.

\section{Define the problem}

Another step in the design thinking process is to define the problem. At this particular point, the analysis of the previously conducted interviews and empathy map took place.

As mentioned previously, an empathy map lays a foundation for other tools creating a customer profile, for example. It is a part of the Value Proposition Canvas (VPC) and breaks the customers down into their jobs, pains, and gains (Osterwalder, Pigneur, Bernarda, \& Smith, 2014, pp. 31-53). Below there is a canvas for the business/big companies group. 
The first category, 'jobs to be done,' covers the tasks the customer is trying to perform (either functionally, socially, or emotionally), customer needs to be satisfied, or problems that the customer is trying to solve (Osterwalder et al., 2014).

The second point in the VPC is the category 'pains,' in which all negative experiences, risks, or emotions that the customer faces while getting the job done are stated (Osterwalder et al., 2014).

Last but not least is the 'gains' category. It describes all the benefits or outcomes that the customer wants (Osterwalder et al., 2014).

Based on the mentioned customer profile and the empathy map, the participants created an HMW (How might we?). It allows the problem to be defined and the aims to be clarified. When creating the HMW questions each team chose the persona name, defined the problem or need, and pointed out the benefit that would be derived from solving the problem.

When it comes to the big company/corporation group, the question created was: How might we help Aleksander to reach the offer of the incubator (start-up), so that he could quickly implement solutions in his company?

The business environment institutions team came up with the following question: How can we help Wiktoria to create a friendly environment for entrepreneurs, so that they play an active part in creating their own business?

A group representing start-ups and medium or small companies raised the following question: How might we help Kondrad to develop his own idea and ensure intellectual property, so as to give him the feeling that he is going in the right direction in starting his own business?

With all the described steps, the groups defined their problems and understood their target so they could move on to the next step: ideating.

\section{Ideate}

This stage was focused on creating solutions responding to previously defined challenges. The techniques used were based on variations of brainstorming, depending on team preferences.

The generated ideas were later divided into the following categories: ideas to throw away, crazy but inspiring, nothing new, and ideas with potential. Analysing the insights, the participants brainstormed for value added ideas to create better opportunities for incubators. The desired outcome was to choose two ideas from all of those generated. The two best ideas were defined based on voting by the group members. All ideas were written on concept cards, which included such information as: title, solution description, value for the customer, the hypothesis being verified, and what needs to be checked additionally. 
Selected ideas were: 'BIZNES-e-kropka' (BUSINESS-e-dot), 'TESTUJ SWÓJ BIZNES' (TEST YOUR BUSINESS), 'PAY OR SHARE,' 'GROSIK BĘDE WINNA' (I WILL OWE A PENNY), 'START-OUT,' I'NKUBAZA' (INCUBASE), 'ZAUFANIE W 5 KROKACH' (TRUST IN 5 STEPS), 'BAZA(R) INKUBATORA' (BASE/BAZAAR OF INCUBATOR).

\section{Prototype}

At a prototype phase, the groups were to visualise the selected ideas. Due to time limitations and the fact that the majority of chosen ideas were based on a website or a portal, the prototype was a video showing the how the tool would work and the vision behind it. Using a video and simple animation to present the idea gave a good view of the utility of the designed tool.

\section{Testing}

The fifth DT stage was testing. Many groups were asked for their opinion and feedback. This phase can be divided into three parts, which took place in different moments in time and in different forms. First of all, the first raw prototypes were shown to the other group members, and feedback was gathered. It is important to remember that the team members were people representing all target groups. The results were documented in test cards, which consisted of four sections: what works, what needs to be fixed, questions, and suggestions.

Tests show that the ideas at this stage were still far from perfect and there was a lot of room for improvement. Some of the ideas needed a more practical or feasible approach and all needed to be polished before achieving their final and usable form. Therefore, the prototypes were refined, and the second part of the test took place.

The finished prototypes were presented to the jury, in which there were people directly responsible for the incubator: Grzegorz Liśkiewicz Ph.D. - rector's plenipotentiary for entrepreneurship, Grzegorz Kierner, and others involved in the topic, such as the vice president of the student council, Paulina Leśniewska. After getting acquainted with the proposals, the jury voted (according to their liking) by ranking the ideas from one to three. The three ideas that appealed to the jury were: 'PAY OR SHARE,' 'BIZNES-e-kropka' (BUSINESS-e-dot), and 'TESTUJ SWÓJ BIZNES' (TEST YOUR BUSINESS).

In the last part of this phase, all eight previously chosen ideas were supposed to be tested on a wide scale (mass scale). The research was planned to be qualitative and based on the test card tool, which means it covered four main questions: What works? What needs to be fixed? What are the questions? And 
what are the suggestions? The last step, the public surveys, was to be conducted by the participants, preferably in the form of an interview with a presentation of videos of the prototypes. The feedback from the online questionnaire, based on the information available at the moment when the observation and process descriptions were completed, indicates that all reviews (there were only a few) ${ }^{1}$ were highly positive with hardly any criticism (it was suggested a few times that all solutions should be merged together). The implementation of this stage was stopped in February 2020 due to the change of the organisers' priorities. Thus, the last stage of widely tested ideas has not been carried out, which does not allow the presentation of its results.

\subsection{Description of the prototyped solutions}

The group that focused on business environment institutions proposed 'BIZNES-ekropka' (BUSINESS-e-dot) and 'TESTUJ SWÓJ BIZNES' (TEST YOUR BUSINESS).

The first idea was a portal in which there would be a calendar with events organised by the business-environment institutions. A representative of such an institution could add an event to the calendar and see when other institutions had planned their events. There would only be the need to choose the date, time, and place and give extra information if necessary. The idea would be to have information about such events in one place. Additionally, on the website, one could promote offers, which would then be placed on the map. One extra feature of the portal is that there would be information about the events, and if a user would be interested in sponsoring any of them, they would be able to use a form and also see the details of the contest, workshop, or other. Moreover, other viewers would be able to see the person's offer.

The second idea, 'TESTUJ SWÓJ BIZNES' (TEST YOUR BUSINESS), would help customers interested in testing a product or service to organise testers. When the interested person would ask the institution for help, it would contact the incubator. The incubator would then organise appropriate testers and, if needed, carry out tests outside of the incubator. The meeting with the customer and the representative of the business environment organisations would be held when all information had been shared and judged by the person in question.

\footnotetext{
1 At this moment, the number of responses to the questionnaire contradicts the concept of widely tested ideas.
} 
The team that had small companies and start-ups as a focus group proposed the solutions 'PAY OR SHARE' and 'GROSIK BĘDE WINNA' (I WILL OWE A PENNY).

The first would be dedicated mainly to the users of the incubator who pay a monthly fee. The 'PAY OR SHARE' option would allow such people to decrease the fee by sharing their knowledge or experience with others. The person would choose what they needed from the incubator and state what they could do in return. By giving detailed information about the offer, the customer could get a calculated discount. For the high quality of service, all such applicants would be verified after filling in the form.

'GROSIK BĘDE WINNA' (I WILL OWE A PENNY) is an idea of a multisided platform in which the users could look for items needed to proceed with business ideas. On the website, the user would choose whether they wanted to look for something or add an offer. Then, they would be asked to state whether it is equipment, knowledge, or a service that they sought and then indicate the form of transaction (e.g. buy, borrow). Finally, a list of offers would be generated and the user could choose the most suitable one. When the customer would be sure of their choice, they could conclude an agreement or a contract and then the transaction would be completed.

The other two ideas were proposed by the team focused on big companies. Their tiles are: 'START-OUT' and 'INKUBAZA' (INCUBASE).

The first solution was a website on which the representatives of big companies could look for either a solution to a problem or a team who could execute the task. The company would then go step by step filling in the form by choosing the business sector, describing the problem, and stating the budget and the deadline. The last step would be to provide contact details and send the form. An expert from the incubator would search for the most suitable solution and contact the customer.

'INKUBAZA' (INCUBASE) is a platform basis of start-ups from all around Poland, in which the director of an enterprise would be able look for a start-up that could provide a solution to the enterprise's problem. The search process would be done using filtering and keywords. Then the customer would be able to look through the offers, check references, and see the draft of a contract. If that would be the desired solution, they would fill in the contact form to inform the start-up about their willingness to cooperate.

The last two solutions are called 'BAZA(R) INKUBATORA' (BASE/ BAZAAR OF INCUBATOR) and 'ZAUFANIE W 5 KROKACH' (TRUST IN 5 STEPS), which were developed by the team whose focus group was students. 
The first idea is a platform upon which students or start-ups would be able to post their products or services for sale without starting a business. The customer could purchase a product or service and review it. Thanks to that, the seller could measure the response and interest based on feedback. Another benefit is that works of unknown authors could be promoted. Additionally, creators could earn money for their products.

'ZAUFANIE W 5 KROKACH' (TRUST IN 5 STEPS) is intended to make the user feel more assured while using services provided by the incubator. There are five steps that a user would be able to follow. The first one would provide information about the incubator. The second would inform the user about the possibilities the incubator offers. The third would introduce activities that the person can do within the incubator. The fourth would inform the user what they and the incubator can do together, and the last step would be to join the incubator. The idea is that after those five steps all doubts would be gone; however, there is also the possibility to ask for advice or explanation from a legal counsel who is cooperating with the incubator.

\section{Discussion}

According to the literature, the growing importance of entrepreneurship is, for the time being, a mainstay tendency. A great number of young people strive to start a business and develop ideas. One of the answers to this phenomenon is an academic business incubator. Therefore, the aim of this paper is to assess the use of DT in the creation of academic incubators and judge its use in the case of creating the incubator at TUL.

As mentioned before, the importance of incubators, especially university incubators, is growing. Universities were forced to fulfil their new mission as actors in business enterprise. The pace of the development and the need for new qualifications among alumni impose changes in the manner of teaching and fostering entrepreneurship. What is more, university incubators stake out an important place among different kinds of incubators. This is mainly due to the resources that the university can provide in hosting the incubator, and the fact that the incubators' tenants are people with modern knowledge and special skills (especially in the case of technical and medical universities). Incubators foster entrepreneurship, which is a trigger for innovation. They are crucial for the development in all aspects of life and work. 
The great benefits of academic incubators are delivered only by well-organised ones. The crucial stage of the incubator creation process is the preliminary phase. In the literature, the stages of this phase are defined as follows: the feasibility study, building support, identifying and securing stakeholders, and identifying a market niche. Those aspects are vital for the proper creation of a successful incubator.

The problem-solving tool used by TUL for creating a business incubator is the design thinking method. The great effectiveness of the method is a result of human-centric design and a deep understanding of customer needs. As has been proven, DT brings benefits in all kinds of industries and in different aspects of work. Therefore, when considering whether DT is a suitable tool for creating an incubator, the answer is 'yes.' This is due to its features and the great innovative potential of the tool, which makes it perfect for creating outstanding and innovative ideas for a venture such as a business incubator. By connecting activities and effects, DT helps avoid proposing activities with no intended effect or anticipating effects with no supporting activities. The ability to spot such mismatches easily is perhaps the main advantage.

The choice of the DT method was highly appropriate for creating solutions for TUL's incubator. As mentioned previously, this method works well in such cases; however, in this particular case, it can be even more beneficial. The university not only obtained innovative solutions at low cost but also promoted the incubator and showed its own innovativeness by using an unconventional tool that has recently become very popular and fashionable.

For participants the common works were an opportunity to share their ideas with other teammates with different perspectives, and to keep in mind why they are doing this and for whom. It was very important to use their knowledge, experience, skills, and needs in the field of collaboration with incubators. Furthermore, the participants had a sense of social contribution to the local people, the university, and community. A creator can talk about this idea, clarify misinterpretations, ask for other opinions, check the assumptions, compare them with research findings, and in the end develop a solid system of incubator services. This prototype then becomes a powerful service for incubators stakeholders. Because users are involved in the process of design thinking from the early stages, it is emphasised to fail early to succeed faster by co-creating the ideas with the users. For TUL, both the incubator itself and the solutions it provides can become great assets. When it comes to the incubator, the university should take into consideration all benefits it can bring from economic, social, and scientific 
perspectives. The workshops organised to seek solutions for the additional functionality of incubator were an excellent idea, perfectly suiting current trends and potentially bringing great profit.

It is important to remember that, in the case of all innovations, timing is an important aspect, which is why TUL should not hesitate to develop the incubator. University incubators have some dominance over different ventures of this kind, but still there are many other similar facilities in Lodz. DT requires the direct involvement of users, who must be put in a position to make their own contribution (availability of time and resources).

The final step before implementation was to test elaborate mass-scale prototypes. Unfortunately, in this project this step failed for various reasons, such as bad user involvement or underestimation of the impact of the initiative on the results. DT did not allow limitation of these risks in this case. Moreover, the implementation of these ideas was suspended due to the change of priorities of the TUL organiser. Sharing rough prototypes helps to foster better service development before spending a lot of time and money to make the final form.

\section{Conclusions}

\subsection{Research contribution}

The idea of building an incubator seems to be not only beneficial for the university students and workers but, as was proven previously, for society. Such a venture is a complex problem that requires good planning and adequate funds. This topic cannot be approached carelessly, and that is true for all universities. However, due to the chosen methodology, more detailed results cannot be generalised. As far as the outcomes of the workshops are concerned, until the moment of creating this paper (April 2019), the process was still in progress; therefore, the implementation of the ideas could not proceed as planned. This stage was not completed and was suspended in February 2020.

In the opinion of organisers, the outcome of the workshops is highly valuable because it indicates a clear direction of development. The created ideas are maverick and interesting, but at the same time fairly easy in the case of implementation and development. Room for improvement exists in previously used solutions, which can be modernised by adding new functionality. What is more, the ideas show the system of cooperation between small start-ups and established investors. The three best solutions are believed to create a key value of the 
incubator. A valuable 'side effect' is the fact that the university authorities noticed the potential of the solutions, and they started to think in an innovative way. It also boosts motivation and involvement in the strategy of building the business incubator. The final prototypes are considered as a great success, the solutions are innovative and at the same time easily implementable, and the teams are so involved that they are willing to continue with further cooperation.

The future development of the solutions is an open issue at this point because there are no exact plans. This results from the fact that there are more important needs, concerning the development of the incubator, which have to be taken care of first. Furthermore, the difficulty with gathering feedback, as mentioned before, caused problems. When the solutions to develop are officially decided, then these solutions will wait for an appropriate time, funds, and the chance for growth.

The solutions created during workshops, as elaborated previously in this paper, can generally be divided into four categories. Those groups are adequate to the target groups from the incubator's environment, which means that solutions are directed at students, small start-ups, big companies, and businessenvironment institutions. The solutions answer the needs of those groups and at the same time, in a more or less direct way, foster entrepreneurship. To summarise, no matter which group is addressed, the outcome is beneficial for the majority, and it fosters entrepreneurship; the only difference is the approach.

The idea of harnessing the potential of design thinking to create a distinctive feature, which will be a key value and unique selling point of the incubator, was a pertinent one. The choice of the focus groups' representatives as participants was very interesting. The design thinking process, as described earlier in this work, was generally followed in an organised and proper manner. What was also beneficial to the workshops was the fact that the hosts were specialists in the design thinking field, so the groups were provided with professional guidance.

Despite all the mentioned positive aspects, there were a few shortcomings: The workshops were lacking when it came to long-term planning: a lack of secured founds and time for implementation of the solutions may make them unusable. Moreover, the testing part in the workshops was poorly prepared, which led to low response numbers.

The method itself turned out to be an excellent choice. 


\subsection{Research implications}

The research shows a great opportunity for practitioners focused on fostering entrepreneurship at universities. Due to the character of the methodology, the results may not serve as a solution in all situations. It does, however, encourage researchers to further develop and implement unconventional tools such as DT.

In this case, the proper choice of method and the well-conducted process is still too little to be fully beneficial for the university. The results need to correlate properly with university strategy, priorities, and ecosystem. The business incubator is a great opportunity to enrich the TUL ecosystem, and the workshops are supporting this movement. The design thinking process is a great tool for finding innovative solutions. Such actions are influencing the way of teaching at TUL by using the first-hand experience of business practices and design for business. Design thinking workshops could become more common at TUL not only as an innovative way of problem solving but also as an innovation in the approach to teaching.

From a scientific perspective, the study provides researchers with a very unique case study example, proving the importance of an unconventional approach to entrepreneurship as well as the wide range of possibilities of DT usage. It also encourages further studies in this field because it is not covered extensively in the literature.

The general conclusion is the same as that made by Allahar \& Sookramthat (2019), which is that progress toward building an effective university-centred entrepreneurial ecosystem has been relatively slow and needs to be accelerated. Greater involvement of internal and external stakeholders is a very important aspect.

\subsection{Research limitations and future works}

Closing this part of the work, it is crucial to mention the limitations of the study. In this case, the limitations are connected strongly with the methodology itself. The case study method, despite its many benefits, has weaknesses, not least of which is the fact that the study may not be suitable for generalisation, and therefore the validity range is limited. As in the case of the majority of qualitative research, the subjective view of the researcher may cause a degree of bias in results (Diamond \& Sigmundson, 1997). Except for the methodology limitations, the main issue was caused by the characteristics of DT; the process 
is a creative one and, in this case, is limited by time. For such purposes, often the tools used are based on previous tools with the use of 'post-it' notes. Hence, not all tools could be documented because they were destroyed in order to be used for the subsequent tool. Part of the documentation was missing; therefore, the study considered mainly the available documents. What is more, authors joined the project in the process, and thus were unable to observe it from the beginning. Therefore, this paper was based mainly on available documentation and users' or organisers' opinions. Because the process was still in progress when this work was created, only the process and its organisation could be assessed, and not the results. The limitation of this study is the lack of widely tested ideas.

It would be beneficial to consider the DT approach in the creation of other institutions in order to prove its usability. Depending on the character of the incubator or other ventures like it, the aims may vary, which can lead to other limitations in the use of the method described in this paper. Interesting future research would be to compare the process of the creation of an incubator with and without usage of the DT method.

\section{References}

Allahar, H., \& Sookram, R. (2019). Emergence of university-centred entrepreneurial ecosystems in the Caribbean. Industry and Higher Education, 33(4), 246-259. https://doi.org/10.1177/0950422219838220

Apanowicz, J. (2001). Metodologia ogólna [General methodology]. Gdynia: WSAiB.

Bąkowski, A., \& Mażewska, M. (2018). Ośrodki innowacji i przedsiębiorczości w Polsce [Innovation and entrepreneurship centers in Poland]. Warszawa: Stowarzyszenie Organizatorów Ośrodków Innowacji i Przedsiębiorczości w Polsce.

Bezerra, E. D., \& Andreassi, T. (2017). Universities, local partnerships and the promotion of youth entrepreneurship. International Review of Education, 63, 703-724. https://doi.org/10.1007/s11159-017-9665-y

Bland, D. (2016). Agile coaching tip: What is an empathy map? Retrieved from https:// www.solutionsiq.com/resource/blog-post/what-is-an-empathy-map/

Bone, J., Allen, O., \& Haley, C. (2017). Business incubators and accelerators: The national picture. BEIS Research Paper, 7, 39-45. Retrieved from https://www. econstor.eu/bitstream/10419/196202/1/2017-07-business-incubators-acceleratorsuk-report.pdf

Diamond, M., \& Sigmundson, K. (1997). Sex reassignment at birth: Long-term review and clinical implications. Archives of Pediatrics \& Adolescent Medicine, 151(3), 298-304. https://doi.org/10.1001/archpedi.1997.02170400084015 
Fjuk, A., \& Kvale, J. K. (2018, June). Developing managerial dynamic capabilities: A quasi-experimental field study of the effects of design thinking training. Academy of Management Learning \& Education, 17(2), 184-202. https://doi.org/10.5465/ amle.2016.0187

Freeman, E., \& Moutchnik, A. (2013). Stakeholder management and CSR: Questions and answers. Umwelt Wirtschafts Forum, 21(1), 5-9. https://doi.org/10.1007/ s00550-013-0266-3

Hackett, S. M., \& Dilts, D. M. (2004). A systematic review of business incubation research. Journal of Technology Transfer, 29(1), 55-82. Retrieved May 12, 2019 from https://search.proquest.com/docview/203654523 ?accountid=28422

Hasso Plattner Institute of Design Stanford. (2010). An introduction to design thinking process guide. Stanford: Author. Retrieved from https://dschool-old.stanford.edu/ sandbox/groups/designresources/wiki/36873/attachments/74b3d/ModeGuideBOOT CAMP2010L.pdf

Jankowska, B. (2015). Cluster organization as a pro-internationalization form of cooperation in the SME sector - a Polish case in the European context. Journal of Economics \& Management, 22(4), 54-74.

Kumar, R. (2011). Research methodology: A step-by-step guide for beginners. London: Sage Publications.

Kuratko, D. F., \& Morris, M. H. (2018) Examining the future trajectory of entrepreneurship. Journal of Small Business Management, 56(1), 11-23. https://doi.org/10.1111 /jsbm.12364

Leydesdorff, L. (2012). The knowledge-based economy and the triple helix model. Annual Review of Information Science and Technology, 44, 367-417. https://doi.org/ 10.1002/aris.2010.1440440116

Liedtka, J. (2014). Perspective: Linking design thinking with innovation outcomes through cognitive bias reduction. Journal of Product Innovation Management, 32(6), 925-928. https://doi.org/10.1111/jpim.12163

Link, A. N., \& Sarala, R. M. (2019). Advancing conceptualisation of university entrepreneurial ecosystems: The role of knowledge-intensive entrepreneurial firms. International Small Business Journal: Researching Entrepreneurship, 37(3), 289-310. https://doi.org/10.1177/0266242618821720

Malecki, E. J. (2017). Entrepreneurship and entrepreneurial ecosystems. Geography Compass, 12(3), 1-21. https://doi.org/10.1111/gec3.12359

Mitra, S. (2013, August 23). The problems with incubators, and how to solve them. Harvard Business Review. Retrieved from https://hbr.org/2013/08/the-problemswith-incubators-a

Osterwalder, A., Pigneur, Y., Bernarda, G., \& Smith, A. (2014). Value proposition design: How to create products and services customers want. Hoboken, New Jersey: John Wiley \& Sons. 
Russell, R. S., \& Taylor III, B. W. (2008). Operations management along the supply chain (6th edition). New York: John Wiley \& Sons.

Saffar, A. M. (2008). Internationalization and business support in Asia-Pacific. In Essay Collection, The 11th International Training Workshop on Business Incubation (pp. 52-59). Invest Shanghai; Shanghai.

Schallmo, D., Wiliams, C. A., \& Lang, K. (2018). An integrated design thinking approach - literature review, basic principles and roadmap for design thinking. In The ISPIM Innovation Conference - Innovation - the Name of the Game (pp. 8-10). Stockholm: ISPIM.

Sherwood, A. (2018). Universities and the entrepreneurship ecosystem. In S. Globerman, J. Clemens (Ed.), Demographics and entrepreneurship: Mitigating the effects of an aging population (pp. 239-282). Vancouver: Fraser Institute. Retrieved from https://ipa.org.au/wp-content/uploads/2018/05/Demographics-and-Entrepreneurship -full-WEB-book-2.pdf

Siegel, D. S., \& Wright, M. (2015). Academic entrepreneurship: Time for a rethink? (ERC Research Paper, No. 32). Retrieved from https://www.enterpriseresearch. ac.uk/wp-content/uploads/2015/07/ERC-ResPap32_WrightSiegal.pdf

Siemieniuk, Ł. (2017). Wybrane aspekty funkcjonowania akademickich inkubatorów przedsiębiorczości w Polsce [Chosen aspects of functioning of academic business incubators in Poland]. Optimum. Studia Ekonomiczne, 6, 81-83. https://doi.org/ 10.15290/ose.2017.06.90.07

Sztrumski, J. (2004). Metoda monograficzna, jej zalety i niedostatki [Monographic methods its strengths and weaknesses]. Zeszyt Naukowy Katedry Socjologii i Psychologii Górnośląska Wyższa Szkoła Handlowa w Katowicach, 25, 7-16.

Urząd Miasta Łodzi. (s.a.). Incubatory i akcelaratory przedsiębiorczości [Business incubators and accelerators]. Łódź: Author. Retrieved from https://uml.lodz.pl/dlabiznesu/dla-przedsiebiorcy/biznes/inkubatory-akceleratory-przedsiebiorczosci/

Ustawa z dnia 20 lipca 2018 r. Prawo o szkolnictwie wyższym i nauce (Higher Education Act 2018, c. 6), t.j. Dz. U. z 2020 r., poz. 85, 374, 695, 875, 1086. Retrieved from http://prawo.sejm.gov.pl/isap.nsf/download.xsp/WDU20180001668/U/D2018 1668Lj.pdf

Wicaksana, D. E. P., Yuniaristando, Y., \& Sutopo, W. (2015). Identification of incubation scheme by incubator in university innovation centre to develop Indonesian economy. In Proceeding of the Joint International Conference on Electric Vehicular Technology and Industrial Mechanical, Electrical and Chemical Engineering (ICEVT \& IMECE) (pp. 292-297). Surakarta: IEEE. https://doi.org/10.1109/ ICEVTIMECE.2015.7496696

Zablocki, E. M. (2007). Formation of a business incubator. In Intellectual property management in health and agricultural innovation: A handbook of best practices (Vol. 2; pp. 1305-1313). Oxford/Davis: MIHR-USA. Retrieved from http://www.iphandbook. org/handbook/chPDFs/ch13/ipHandbook-Ch\%2013\%2006\%20Zablocki\%20

Business\%20Incubators.pdf 